\title{
Acute stress disorder with panic episodes induced by exposure to COVID-19 outbreak news in a child
}

\author{
Duygu Kaba ${ }^{1 \oplus}$, Burcu Akin Sari ${ }^{1 \oplus}$ \\ 'Baskent University Faculty of Medicine, Department of Child and Adolescent Psychiatry, Ankara - Turkey
}

\section{Dear Editor,}

Since the initial outbreak in Wuhan, China, was reported in December 2019, Coronavirus disease (COVID-19) has spread to several countries, including Turkey, and has been declared a pandemic by the World Health Organization (1). The first case in Turkey was confirmed in March 2020. Since the day of its first detection, the disease has been frequently mentioned in the media and there are now innumerable news reports of deaths in many countries.

Many children hear conversations related to Coronavirus and are worried when they see people outside their homes wearing masks. News of this outbreak affects children with different biopsychosocial characteristics to varying degrees (2).

This report presents a 10 -year-old patient with anxiety disorder who experiences panic attacks triggered by news of the COVID-19 outbreak.

A 10-year-old male fifth-grade elementary school student was admitted to our clinic due to intense concerns related to Coronavirus during the past month. In his interview, the patient indicated that he was afraid of Coronavirus coming to Turkey, that he or his family would get sick, and that whenever Coronavirus was mentioned he would experience intense emotional distress, increased heart rate, shortness of breath, nausea, crying, and the need to speak with his mother or father when in distress, and that he would call his parents from school and would only feel better after speaking with his family. Since Coronavirus was not mentioned much at home, he would feel relatively better there; however, his distress increased especially at night and he would cry. Lately, he was feeling unhappy, he did not want to go to school because his friends often mentioned the Coronavirus outbreak, and he would vomit in the morning when going to school. His mother indicated that despite being an academically successful and responsible student, after hearing of the Coronavirus outbreak, he was unwilling to do his homework; he was lately experiencing sleeping difficulties, woke up early in the morning, and had decreased appetite. The patient had not presented to a psychiatric clinic previously. Family history revealed that the patient's father had a diagnosis of panic disorder and was using paroxetine.

Psychiatric Examination: The child looked appropriate for his age, his clothing was compatible with his socioeconomic level, and his self-care was adequate. He avoided eye contact from time to time, and he showed a timid attitude when communicating. He answered questions with simple content. His mood was anxious, his affectivity was consistent with his thought content. The thought process was normal; it contained themes about coronavirus fears. His attention and perception were normal. His intelligence gave the impression of being clinically normal.

The patient's State-Trait Anxiety Inventory state score was 61 , the trait score was 68 , and Children's Depression Inventory score was 21 . The patient was diagnosed with "Acute stress disorder with panic episodes" according to the Diagnostic and Statistical

How to cite this article: Kaba D, Akin Sari B. Acute stress disorder with panic episodes induced by exposure to COVID-19 outbreak news in a child. Dusunen Adam The Journal of Psychiatry and Neurological Sciences 2020;33:221-222.

Correspondence: Duygu Kaba, Baskent University Faculty of Medicine, Department of Child and Adolescent Psychiatry, Ankara - Turkey Phone: +90 31220368 68-1268 E-mail: duygukaba72@gmail.com 
Manual of Mental Disorders, fifth edition (DSM-5), and was started on $20 \mathrm{mg}$ /day fluoxetine.

It has been reported that psychological problems, including anxiety, depression, and stress, increased during the Covid-19 outbreak (3), and people can still suffer from varying degrees of stress disorders even after the causative event is over (4). Uncertainties regarding the affected geographic areas and the extent of the COVID-19 outbreak, the rapid spread of the disease, and hundreds of daily news reports of deaths have led to significant stress and anxiety. Images unrelated to the disease and the sharing of unfounded news on social media have further contributed to this fear (5).

The main causes of children's fear of the coronavirus include their lack of information related to the virus, acquiring wrong information from their peers, and excessive exposure to news media. Children may incorrectly interpret what they hear and may fear what they do not understand. For this reason, parents and clinicians should inform children about Coronavirus, without going into too much detail, in a manner appropriate to their level of development. For instance, when our patient was asked what he knew about the Coronavirus, he stated that when the virus enters the body, it will cause the person to faint and die in a short period of time.

Retrospective studies have reported that news can have traumatic effects on children (6). It has been indicated that exposing children to frightening instances reported in the media may lead to physical, emotional, and cognitive problems of increased anxiety (7).

Persons with mental problems are more affected by the emotional responses to the COVID-19 outbreak due to their hightened susceptibility to stress compared to healthy individuals, which may cause an already existing mental health condition to recur or worsen (8). While our patient had been recognized as an anxious child since he was very young, after hearing news of the Coronavirus outbreak, his anxiety significantly increased and his functionality was impaired.

Panic disorder, generalized anxiety disorder (GAD), specific phobia, and posttraumatic stress disorder were all considered in differential diagnosis; however, in panic disorder panic attacks occur unexpectedly without a trigger (such as mention of Coronavirus), and the patient had shown good functionality until one month ago, therefore ruling out diagnoses of GAD and specific phobia.
The patient had intrusive thoughts about Coronavirus, experiencing psychological distress and showing physiological symptoms in response to internal or external cues reminding him of the virus; he felt unhappy, avoiding coronavirus-reminding situations while having problems with concentration and sleep, and he had shown symptoms of Trauma and Stressor-Related Disorders according to DSM-5 for around one month and described panic attacks. Accordingly, he was diagnosed with "Acute stress disorder with panic episodes."

The patient's father's diagnosis of panic disorder led us to consider the future risk for the patient to develop panic disorder himself. It is crucial to follow up such patients for a sufficient period of time and observe the clinical course and treatment response in order to confirm the final diagnosis. This report is relevant because it demonstrates the stress and anxiety that the COVID-19 outbreak may cause in children. As far as we know, this is the first case report on the subject.

Informed consent: Written informed consent for the publication of this case was obtained from the patient and his family.

Conflict of Interest: The author declares that there is no conflict of interest.

Financial Disclosure: No funding declared.

\section{REFERENCES}

1. Mahase E. Covid-19: WHO declares pandemic because of "alarming levels" of spread, severity, and inaction. BMJ 2020; 368:m1036.

2. Taylor S. The Psychology of Pandemics: Preparing for the Next Global Outbreak of Infectious Disease. Newcastle upon Tyne: Cambridge Scholars Publishing, 2019.

3. Lima CKT, Carvalho PMM, Lima IAAS, Nunes JVAO, Saraiva JS, de Souza RI, et al. The emotional impact of Coronavirus 2019-nCoV (new Coronavirus disease). Psychiatry Res 2020; 287:112915.

4. Duan L, Zhu G. Psychological interventions for people affected by the COVID-19 epidemic. Lancet Psychiatry 2020; 7:300-302.

5. Ren SY, Gao RD, Chen YL. Fear can be more harmful than the severe acute respiratory syndrome coronavirus 2 in controlling the corona virus disease 2019 epidemic. World J Clin Cases 2020; 8:652-657.

6. Harrison $\mathrm{K}$, Cantor J. Tales from the screen: enduring fright reactions to scary media. Media Psychol 1999; 1:97-116.

7. Hoge E, Bickham D, Cantor J. Digital Media, Anxiety, and Depression in Children. Pediatrics 2017; 140:S76-S80.

8. Yao $\mathrm{H}$, Chen JH, Xu YF. Patients with mental health disorders in the COVID-19 epidemic. Lancet Psychiatry 2020; 7:e21. 